\title{
Tobacco Smoking and Risk of Novel Coronavirus Infection
}

\author{
Anusha Dubey ${ }^{1}$, Deepak Saini ${ }^{1}$, Shubham Roy ${ }^{2}$, Ram Pukar Bharat ${ }^{3}$, \\ Veronika Bentrad $^{4}$, Callum Yau ${ }^{5}$, Isaac George Wallbridge ${ }^{5}$, Abhishek Shankar ${ }^{6}$
}

${ }^{1}$ Cancer Control and Prevention Division, Indian Society of Clinical Oncology, Delhi, India. ${ }^{2}$ Department of Pediatrics, Sitaram Bhartia Institute of Science and Research, Delhi, India. ${ }^{3}$ Department of Radiation Oncology, All India Institute of Medical Science, Patna, India. ${ }^{4}$ Department of Tumor Biochemistry and Oncopharmacology R.E. Kavetsky Institute of Experimental Pathology, Oncology and Radiobiology NAS of Ukraine, Kyiv, Ukraine. ${ }^{5}$ Academic Unit of Medical Education, The University of Sheffield, United Kingdom. ${ }^{6}$ Department of Radiation Oncology, Lady Hardinge Medical College \& SSK Hospital, Delhi, India.

\begin{abstract}
Tobacco consumption, specially smoking and waterpipe, affect the lung capacity which may lead to difficulty in breathing, caused by long term harmful effect on cardiovascular and respiratory system leading to elevated risk of various kind of infectious diseases. SARS-CoV-2 infection, which primarily affects the lungs, is found to be associated with severe events in persons who consume tobacco either smokeless or with smoke. Many studies showed that smokers, either current or former, show the severe COVID-19 progression. Yet there is no strong evidence which establishes the link between tobacco smoking and COVID-19. Smoking causes increase in secretory cells of respiratory tract, subsequently increasing ACE-2 expression. Ageing is also associated with a higher expression of ACE-2 gene. This can possibly explain the vulnerability of aged people, smokers and patients with hypertension to coronavirus and also people who consume tobacco, either smokeless or smoke, as a potential vulnerable group for COVID-19.
\end{abstract}

Keywords: Tobacco- smoking- COVID-19- SARS-CoV-2- Coronavirus infection

Asian Pac J Cancer Care, 5 (Suppl 1), 175-177

Submission Date: 06/15/2020Ａcceptance Date: 07/04/2020

\section{Introduction}

Coronavirus disease 2019 (COVID-19), caused by a type of coronavirus known as Severe Acute Respiratory Syndrome Coronavirus 2 (SARS-CoV-2), has emerged as a public health crisis. Till mid-June 2020, the most affected countries like USA, Brazil, Russia, India, UK, Spain and Italy have reported more the $50 \%$ of 7.5 million COVID-19 cases. The overall mortality due to COVID-19 is reported close to half of million people, making it the biggest public health crisis of current era [1]. Initially thought to be primarily a disease affecting lung and causing pneumonia, now found to be involving various tissues and systems including causing thromboembolism, stroke and renal failure.

Though, coronavirus infection is affecting all age groups, sex, race, ethnicity and continents, few groups or people are more susceptible to getting infected with coronavirus and few of them have higher chance of adverse disease progression including death. The risk factors for
COVID-19 are old age people having co-morbidities including diabetes, hypertension, cancer, respiratory diseases, cardio-cerebrovascular diseases and renal diseases. Patients with these co-morbidities are found to be at a higher risk of severe COVID-19 progression including deaths [2].

Tobacco smoking is a known major risk factor associated with many of these disease conditions, especially related with respiratory system [3]. Tobacco consumption, specially smoking and waterpipe, affect the lung capacity which may lead to difficulty in breathing added by long term harmful effect of cardiovascular and respiratory system leading to elevated risk of various kind of infectious diseases [4]. Severe Acute Respiratory Syndrome Coronavirus 2 (SARS-CoV-2) infection, which primarily affects the lungs, is found to be associated with severe events in people who consume tobacco either smokeless or smoke. Yet there is no strong evidence

Corresponding Author:

Dr. Deepak Saini

Cancer Control and Prevention Division, Indian Society of Clinical Oncology, Delhi, India.

Email: nickdeepak24@gmail.com 
which establishes the link between tobacco smoking and COVID-19.

Tobacco is being consumed worldwide in various forms which include tobacco chewing, paan masala, bidi, taibur (liquid water), cigarette smoking etc. Thus, people who consume tobacco are also found to be at an increased risk of contracting SARS-CoV-2 infection. The reason behind smoking being a risk factor for COVID-19 can be linked with Angiotensin-converting enzyme II (ACE-2). Expression of ACE-2 gene is increased in people who smoke. ACE-2 is found to be associated with SARS-CoV-2, which uses it as a receptor for cellular entry. Smoking causes an increase in secretory cells of respiratory tract, subsequently increasing ACE-2 expression [5]. Ageing is also associated with a higher expression of ACE-2 gene [4]. This can possibly explain the vulnerability of aged people, smokers and patients with hypertension to coronavirus and person who consume tobacco, either smokeless or smoke, as a potential vulnerable group for COVID-19.

Tobacco smoking makes respiratory system prone to many infections. Consumption of tobacco, either smoke or smokeless, is responsible for destroying the cells of immune system as reported in many studies showing that smokers are more prone to the allergic symptoms (influenza like) and higher deaths recorded in previous Middle East Respiratory Syndrome Coronavirus (MERS-CoV) outbreak among smokers in comparison to non-smokers [4]. Smoking and consuming smokeless tobacco products can possibly correlate with the severities of COVID-19 morbidities, as many evidence based studies highlighted the negative impact of these products on lungs health including COPD (Chronic obstructive Pulmonary Disease), severe degree of pneumonia and cancer, on heart including coronary heart disease, stroke and hypertension [3-6].

Higher rate of severe events are found in people who are infected with coronavirus, and having co-morbidities like hypertension, cancer, diabetes, respiratory problems [2]. Tobacco smoking is associated with higher rate of severe events in Coronavirus disease (COVID-19). In US, around 7162 cases of COVID-19 with complete history of health related data found that $3.6 \%$ of cases were current or former smokers and contributes to $6 \%$ and $8 \%$ cases of hospitalized and Intensive Care Units (ICUs) admission, respectively [7]. Many of the studies conducted in China also reported higher ICU admission rate of patients having history of smoking, either current or former [4].

According to Chinese research study, smokers, either current or former, show the severe COVID-19 progression. In all patients with severe disease progression, every 1 out of 5 was a smoker, $16.9 \%$ current and $5.2 \%$ former smokers, while only $11.8 \%$ current and $1.3 \%$ former smokers were found with non-severe COVID-19 symptoms [8]. Many observational studies found that percentage of smokers is $1.4-18.5 \%$ of hospitalized cases of COVID-19 and severity of COVID-19 is higher among them with an odds ratio of 2.2 [9].

Another research study of china shows that the progression (symptom severity) group had a significantly higher proportion of patients with a history of smoking than the improvement/stabilization group ( $27.3 \%$ vs. $\left.3.0 \%, \chi^{2}=9.291, \mathrm{P}=0.018\right)$. The progression group was found to receive higher respiratory support in comparison to the other group [10].

Smoking is the biggest cause of lung cancer in developed and developing countries. Patients with lung cancer were found at a higher risk of coronavirus transmission among all cancer types with an increased risk of severe events and deaths. Among all the deaths in patients with cancer due to COVID-19, deaths in patient with lung cancer contribute highest [4].

The world is already facing burden of tobacco related diseases and COVID-19 may be the new entry in this. Though there are limited studies available which show the severity of COVID-19 progression and outcome in people with tobacco consumption, and more robust data is needed to establish the relation, but in view of the current pandemic, evidence suggests implementing tobacco control and smoking cessation strategies more strictly to reduce further burden.

\section{References}

1. Johns Hopkins University \& medicine J. 2020. Johns Hopkins University \& medicine: Coronavirus resource centre [Online]. Available: https://coronavirus.jhu.edu/map.html [Accessed June 12 2020].

2. Shankar A, Saini D, Roy S, Mosavi Jarrahi A, Chakraborty A, Bharti SJ, Taghizadeh-Hesary F. Cancer Care Delivery Challenges Amidst Coronavirus Disease - 19 (COVID-19) Outbreak: Specific Precautions for Cancer Patients and Cancer Care Providers to Prevent Spread. Asian Pacific Journal of Cancer Prevention. 202003 01;21(3):569-573. https://doi.org/10.31557/apjcp.2020.21.3.569

3. National Center for Chronic Disease P, Health Promotion Office on S, Health. Reports of the Surgeon General. The Health Consequences of Smoking - 50 Years of Progress: A Report of the Surgeon General. Atlanta (GA): Centers for Disease Control and Prevention (US); 2014..

4. Shankar A, Saini D, Bhandari R, Bharati SJ, Kumar S, Yadav G, Durga T, Goyal N. Lung cancer management challenges amidst COVID-19 pandemic: hope lives here. Lung Cancer Management. 202005 01; https://doi.org/10.2217/lmt2020-0012

5. Smith JC, Sausville EL, Girish V, Yuan ML, Vasudevan A, John KM, Sheltzer JM. Cigarette Smoke Exposure and Inflammatory Signaling Increase the Expression of the SARS-CoV-2 Receptor ACE2 in the Respiratory Tract. Developmental Cell. 2020 06;53(5):514-529.e3. https://doi. org/10.1016/j.devcel.2020.05.012

6. Centers for Disease C, Prevention, National Center for Chronic Disease P, Health P, Office on S, Health. Publications and Reports of the Surgeon General. How Tobacco Smoke Causes Disease: The Biology and Behavioral Basis for Smoking-Attributable Disease: A Report of the Surgeon General. Atlanta (GA): Centers for Disease Control and Prevention (US); 2010.

7. CDC. Centre for Disease Control \& Prevention - Preliminary Estimates of the Prevalence of Selected Underlying Health Conditions Among Patients with Coronavirus Disease 2019 - United States, February 12-March 28, 2020. MMWR Morb Mortal Wkly Rep. 2020;69:382-6.

8. Guan W, Ni Z, Hu Y, Liang W, Ou C, He J, Liu L, Shan H, 
Lei C, Hui DS, Du B, Li L, Zeng G, Yuen K, Chen R, Tang

C, Wang T, Chen P, Xiang J, Li S, Wang J, Liang Z, Peng Y, Wei L, Liu Y, Hu Y, Peng P, Wang J, Liu J, Chen Z, Li G, Zheng Z, Qiu S, Luo J, Ye C, Zhu S, Zhong N. Clinical Characteristics of Coronavirus Disease 2019 in China. New England Journal of Medicine. 202004 30;382(18):17081720. https://doi.org/10.1056/nejmoa2002032

9. WHO. World Health Organization: Smoking and COVID-19 2020 [updated 26 May 2020; cited 2020 June 12]. Available from: https://www.who.int/news-room/commentaries/detail/ smoking-and-covid-19..

10. Liu W, Tao Z, Wang L, Yuan M, Liu K, Zhou L, Wei S, Deng Y, Liu J, Liu H, Yang M, Hu Y. Analysis of factors associated with disease outcomes in hospitalized patients with 2019 novel coronavirus disease. Chinese Medical Journal. 2020 05;133(9):1032-1038. https://doi.org/10.1097/ cm9.0000000000000775

\section{(c) (1) (9)}

This work is licensed under a Creative Commons AttributionNon Commercial 4.0 International License. 